•植物园定位与发展战略专题・

\title{
从博物学视角推进植物园的植物文化传播
}

\author{
刘华杰 ${ }^{*}$ \\ (北京大学哲学系, 北京 100871)
}

\begin{abstract}
摘要: 塞奥弗拉斯特、雷、怀特、林奈、梭罗、缪尔所属的博物学认知传统曾推动植物学、生态学、保护生物学 的创立和发展, 在科学日益专门化的今天, 它也能启发植物园改进植物文化传播工作。植物园工作中重启古老的 博物学, 有助于平衡人类中心论与非人类中心论、科学家视角与公众视角、公共知识与个人知识、外来种与本土 种、驯化与野性等之间的张力。各植物园首先应当重视本土种的保护和展示, 同时面向公众的导赏活动又不必圈 于固定边界的园区, 完全可以扩展至所在地的各种步道, 来探究植物和生态, 欣赏大自然之美。这也为改革植物园 的体制和员工培训提出了新要求。
\end{abstract}

关键词：博物学; 植物文化; 个人知识; 本土知识; 步道植物导赏

\section{Promoting plant culture communication in a botanical garden from a natural history perspective}

\author{
Huajie Liu* \\ Department of Philosophy, Peking University, Beijing 100871
}

\begin{abstract}
The natural history cognitive tradition that Theophrastus, John Ray, Gilbert White, Carl Linnaeus, Henry David Thoreau, and John Muir belong has facilitated the birth and development of botany, ecology, and conservative biology, and when science is increasingly specialized, it seems to inspire experts of botanical gardens to promote plant cultures communication. Restarting and incorporating traditional natural history in the operation of a botanical garden will help balance the tension between anthropocentrism and non-anthropocentrism, scientist and the public perspective, public and personal knowledge, introduced and indigenous species, and domestication and wildness. Every decision in botanical gardens should prioritize conservation and highlight native species. Meanwhile, guided tours of plants should not be restricted to areas of botanical gardens with fixed borders, and the guides of botanical garden and visitors could be able to walk on local trails to look at wild plants, enjoy the ecological landscape, and experience the beauty of nature. However, this suggestion requires reforming the administrative arrangement and staff training of most botanical gardens.
\end{abstract}

Key words: natural history; plant cultures; personal knowledge; indigenous knowledge; trails plants guide

植物园不是单纯的科研单位，它有许多使命， 如引种更多更美的植物供人们欣赏、研究。洪德元 先生撰文通过“三个哪些”来强调新形势下植物园要 特别考虑的几个问题: 引种收集了哪些、培育开发 了哪些、挽救了哪些植物(洪德元, 2016)。洪先生简 洁的文章虽然不尽全面却非常有启发性, 实际上提 出了考核植物园的三个指标。下面笔者从博物的角
度谈改进植物园工作的可能性。

博物学涉及宏观层面人对自然世界的观察、记 录和利用, 考察对象主要是星空、植物、动物、矿 物、岩石、其他物产和生态系统, 相对于现在的还 原论, 自然科学还不够深刻, 但自有其特点和长期 存在的理由。博物学是一门古老学科和文化传统 (French, 1994; Anderson, 2013), 词组historia natu- 
ralis (对应于英文natural history)中, historia不是 “历史”而是“探究”的意思。古人若不擅长博物, 不 了解周围的世界, 便无法生存。亚里士多德的大弟 子、西方植物学之父塞奥弗拉斯特(Theophrastus)就 写过Historia Plantarum, 相当于Enquiry into Plants, 即《植物探究》。之后老普林尼、切萨尔皮诺、雷、 林奈、裕苏、班克斯、达尔文、格雷、梭罗、谭卫 道、洛克、牧野富太郎、E. H. 威尔逊、E. O. 威尔逊 等都是著名的博物学家。历史上博物学也曾辉煌过 (Barber, 1980; Farber, 2000), 但随着分科之学的发 展, 作为自然科学四大传统之一的博物传统在主流 学术界中逐渐边缘化(刘华杰, 2012, 2014, 2016)。虽 然动植物分类学、动物行为学、生态学、保护生物 学等依然带有强烈的博物色彩, 但整体上看博物类 学科显得力量不强、地位不高。

在17-19世纪, 博物类探究有相当一部分走向 专业化道路, 由此演化出一系列现代学科, 如地质 学、动物行为学、古生物学、植物分类学等, 长期 以来这一进程被科学家和科学史家视为理所当然, 被认为是“进步”的表现。不过, 近几十年, 有越来越 多的学者意识到, 事情没有那么简单, 艾伦的一项 社会史研究展示了更丰富也更可信的画面(Allen, 1994)。如此高度简化的进程有得有失, 无法被划归 为当代科学的部分在高校和研究所被严重忽视。回 顾历史发现, 科学与博物学相关并有交集, 但互不 隶属。博物学始终是平行于科学的事业, 过去、现 在博物学都不能还原为纯科学, 将来也不大可能 (Jardine et al, 1996; 刘华杰, 2017)。达尔文、洪堡、 迈尔、古尔德、威尔逊是博物学家, 大量的平民百 姓也可以是博物学家, 介于中间的怀特 (Gilbert White)、米什莱(Jules Michelet)、卢梭、歌德、梅特 林克、缪尔、奥尔森、贝斯顿、巴勒斯等也是。如 今, 科学共同体中一些人仍有博物情怀; 博物学家 群体更为复杂, 有的科学基础扎实, 有的则基本不 懂科学。

不同身份的人对于如何办植物园、如何欣赏植 物都有自己的见解。如今博物学对于推进学术研 究、改造大自然而言远不如科学高效, 但是它对于 传播植物文化、对于公众感受“杨柳依依、雨雪霏 霏”, 增强家园意识, 以及激发普通人热爱植物和 保护植物之情感与行动, 仍有着特殊的作用。最近 几十年, 文化史、科学史、环境史界对于博物学的
“二阶”学术兴趣陡增(Bridson, 2008), 越来越多的 人认识到即使为了生态学、保护生物学这些纯科学 的发展, 博物传统留下的大量优美文本仍然值得在 校理科学生阅读(Graham et al, 2011)。

植物园工作相当复杂, 目标并不仅限于当下的 科学, 有些可能着眼于未来的科学, 更有大量内容 仅与科学相关却不属于科学。另外, “植物文化传播” 不同于 “对植物科学的传播”, 前者包括的内容更 多。仅习惯于从科学角度规划和考核植物园工作, 有可能限制了眼界。其实植物园工作有很强的博物 色彩, 若能主动借鉴上千年的优秀博物学文化传统, 工作可能做得更有生气, 也更受到当地民众的支 持。重启古老的博物学进路, 也会启发植物园解放 思想、转变观念, 平衡不同视角的张力, 走出一条 新路。

\section{1 追求自然性, 尝试非人类中心论}

博物学在价值观上一般说来延续了更多的传 统元素, 在改造自然方面趋于保守(也有个别激进 的)。在博物学家看来, “天地有大美而不言”、“自然 全美”、“大自然是分形(fractal)的”, 而人为作品不具 有这样的特点。大自然在不断演化, 植物是缓慢演 化出来的精致生命体, 大自然本身具有内在价值和 生存智慧。人虽然可以改造自然, 但也应当尊重、 顺应大自然，即使主张征服自然的培根也提及了这 一点。

植物园面对公众, 要普及植物科技知识, 还要 关注文化、历史、习俗、信仰等内容，可能后者更 为重要。准确讲, 植物园要以公众喜闻乐见的方式 做好植物文化传播工作。“植物文化”的概念要比植 物知识的概念广得多, 涉及民族植物学、药用植物 学、园艺、自然美学、环境伦理学、植物分类学、 植物解剖学、植物地理学等许多方面。

过去, 人类中心论在植物园界占主导地位, 在 对待植物的态度和处置手段上皆有明确体现, 强调 植物无条件为人类服务, 也会不自觉地认为引进的 植物一定优于本土植物。但是非人类中心论也颇有 吸引力, 客观上有利于人们从长计议、考虑可持续 利用。尝试从非人类中心论思考问题, 恰好表征人 类理性的擢升, 表明人类具有了良好的生态意识, 在演化中走向了成熟。植物文化传播者在观念上可 提倡博物学家利奥波德的说法: 对待植物, 要从商 
品(commodity)的视角升华为共同体(community)的 视角(Leopold，1949)。即植物不仅仅是可供人类使 用的物品、商品, 它同时是一个巨大共同体的成员, 我们人类与植物同属于此共同体。简单讲, 天人共 生的视角就是非人类中心视角, 这本来就是中国古 代思想家的想法, 没有任何神秘之处。

从博物学的眼光看, “巧夺天工” 是自欺欺人, 人造的植物园再好也不如大自然本身好。以前相当 长时间里, 人类造园显然更多地倾向于人为、人工。 现在要反省一下, 要适当重视所建植物园的野性、

天然性。过度“干净”、人为化的植物园, 可能是无 趣的, 最终科学上也是不合理的。植物园是人造的, 不可避免地有相当多的人为成分, 但可以做到依据 自然、顺应自然。人造的森林、草地虽然某个指标 非常突出, 能够立即满足人们的需求, 但是综合指 标则远不如自然演化的森林、草地, 特别是在生物 多样性上, 有着根本不同。选择河北崇礼一个普通 的山坡, 从春到秋每周去观察, 都会看到不同的景 象, “大戏”一幕幕在上演, 一批长起来开始绽放, 到 下一周它们完全退居二线, 新的一批不同的物种成 为主角, 在舞台上尽情表演, 而再过一周, 它们也 让位于新的演员。这还仅仅是宏观上肉眼观察, 如 果作一个剖面观察地下根系、细菌差别更令人震 惊。植物园建设在向大自然学习、“仿生”方面, 有 太多可以做的工作。举例来说, 栽种新植物要顺势 而为, 园区应当尽可能不使用化学杀虫剂, 要减少 外源草坪的面积。即使喜欢草地, 也要以本土种为 主, 通过修剪自然而然地打造出当地的草地。权衡 好天然与人为, 涉及植物园的功能定位, 非常复杂, 也存在争议。此处只讲了一个笼统的原则, 旨在提 醒当事者思考。“度”的把握宜建立于观念变革、深 入研究、价值权衡和判断力之上。

需要指出一点, 博物学依据的通常是来自经验 的难以量化的“好感觉”, 而非科学意义上坚实的论 据。事后看, 虽然有些好感觉转化成了科学, 但当 初它们并不以科学的面目呈现。好感觉在先, 科学 在后。当然, 并非博物学的感觉都那么好, 这与 科学界的科学并非都正确一样, 无需另外解释。

\section{2 服务公众, 不忽视大尺度}

植物园为谁服务, 并非仅仅是个政治正确的问 题, 而是一个真实的、直接影响到植物园定位的大
事情。千百年来植物园服务的对象一直在变化, 对 象的范围总体上在扩大并变得多样化。长远看, 都 能以“人民的名义”来论证来操作，但具体展开便有 利益冲突。即使考虑大多数人的综合利益, 结果也 依赖于模型，依赖于时空尺度。

植物园工作有一部分是为科研考虑的, 即为科 学共同体中的植物学家或其他专家服务的。对于有 一定条件的植物园, 这显然是合理的。但是从博物 学的视角看, 科研不应当是植物园的最主要任务。 在公众中培养未来的植物学家, 也仅仅是植物园的 一个附带功能。保存和展示特别的物种, 让公众接 触植物、了解一定的知识, 进而培育对植物、对大 自然的情感, 从而丰富日常生活也有利于生态健康, 也是植物园的重要职责。

专家有向公众传播植物知识、引导植物审美的 任务。比如通过介绍生物多样性和民族文化多样性 向百姓展示什么植物是特别的、美的、值得专门保 护的, 通过演化论解说植物的结构何以如此精致。 同时也要兼顾百姓的其他需求, 比如如何分辨常见 植物、一些植物是否可食、如何栽培等。公众通常 并不掌握复杂的科学理论, 但他们可能也并不缺少 植物经验和对植物的感受力, 而经验本身就是重要 的, 其意义不只是服务于科学理论, 如盖伊在《感 官的教育》(Gay, 2015)中所言: “一种经验就是心灵 与世界的一次际遇”, “经验决非仅仅是为思想和行 动提供各种既定而熟知的场景”。经验具有相当的 主观性, 在传统科学观看来多少有些缺陷, 然而在 新科学观看来, 自然科学依然是人的科学, 科学定 律终究不是自然定律, 也只能在建构的意义上才讲 得通。另外, 公众也有能力不借助过多的专业术语 而搞懂有关过程、对相似种作出准确的区分。重要 的是讲解人员要更多地学会使用通俗易懂的语言。 比如讲解全叶马兰(Kalimeris integrifolia)、蒙古马兰 (K. mongolica)、山马兰 $(K$. lautureana) 三者的差异, 完全可以直接根据茎中部叶的形态, 讲清楚叶边缘 的不同, 让人人都能做出明确的区分。

百姓容易短视, 专家也未必不短视, 特别是利 益相关时。但经过科学训练的专家理论上应当看得 更远。博物学家能否看得更远些、权衡的尺度更大 些? 博物学擅长宏观考察、注重生态系统内在联系 的特点决定了博物学家有可能看得更远些。怀特、 梭罗、缪尔、利奥波德也确实如此, 他们考虑问题 
的尺度要更大些。比如“国家公园”这一重要概念就 出自博物学家缪尔, “生物多样性”这一重要概念也 是借博物学家威尔逊之口广泛传播开来的(虽然他 并非原创)。建设植物园要从百年甚至千年的尺度, 不能仅从今年、明年、五年的尺度考虑问题。乔木 的栽种, 至少要考虑 50 年后它们可能会怎样, 值不 值得栽种, 栽种在园区的哪些地方比较合适。按照 博物学的眼光, 引进物种要特别谨慎, 比如火炬树 (Rhus typhina)、互花米草(Spartina alterniflora)、加 拿大一枝黄花(Solidago canadensis)之类就不能轻易 引进。北方的园林就不要太多引进南方的植物, 北 京大规模引种荷花玉兰(Magnolia grandiflora) 就是 一种不恰当的行为, 虽然清华北大校园中有个别成 活者, 但不宜把它作为行道树广泛栽种。珙桐 (Davidia involucrate) 也类似, 它虽是国宝级物种, 却不适合在北京户外大量栽种, 主要是湿度不合 适。中国媒体时有报道成功引种珙桐的消息, 却不 跟踪报道随后它们如何一株株地枯死。科技创新倡 导植物利用, 但不应当诱导公众对植物资源进行毁 灭性开发, 如红豆杉(Taxus chinensis)、铁皮石斛 (Dendrobium officinale)等案例都是教训。对于当下 争论较大的转基因, 博物学家通常持保守意见, 他 们的犹豫或担心是否有道理呢?

不过, 博物学家与科学家在相当多的情况下理 念是一致的。理想的情况是, 所有科学家, 特别是 植物学家、动物学家, 都应当同时是博物学家、具 有博物情怀。

\section{3 立足本土养园, 促进公众热爱、了解家乡}

植物园长期以来十分注重引进外来植物，一定 程度上急慢了本地植物。各地各园程度不等, 有的 相当严重。需要进行一次范式变革(paradigm shift), 彻底扭转这种局面。

收集甚至掠夺别人的资源, 特别是遥远地方的 新奇物种, 是地理大发现、资本主义扩张时期非常 时尚的行为, 不少博物学家也卷入其中, 有的还成 为急先锋。英国邱园是这方面的代表。现在时代变 了, 博物学的理念也变了, 原来的许多做法要改 变。比如爱丁堡皇家植物园帕特森(David Paterson) 现在的做法就与 19 世纪 20 世纪初西方人的做法很 不同, 他在云南就地建园保护珍稀植物, 而不是把 植物全都带回自己的国家。
与巧取豪夺不同但仍有类似倾向的是, 通过购 买和赠予而收集、栽培、展示非本地或域外的植物。 这是直到目前为止多数植物园的常规做法。但是, 这样做会出现两个严重问题: 一是全世界的热带温 室物种雷同。热带温室造价很高、维护成本很大, 但 效果并非都很理想。二是在园区户外各个植物园引 进的物种重复比例较大, 外来的“好”植物大家纷纷 引种。外地植物来到当地, 对水土、气候的适应性 非常不确定, 有些成了入侵种, 有些很娇贵, 照顾 起来耗财费力。更严重的是, 这样厚此薄彼会导致 本土种被忽视, 大众没机会了解家乡的植物。

许多人已经意识到顺序要颠倒过来: 一个植物 园应当优先引种当地的特色植物, 努力向公众介绍 相关知识、展示其美丽。在有余力的情况下, 考虑 引入其他地方的物种, 不可本末倒置。如果各地的 植物园, 无论大小, 都负起责任来, 优先保护、引 种、展示本地的植物, 综合起来, 全国、全球的生物 多样性保护也就有了保障。这样, 植物爱好者参观 不同地方的园林，也能看到更多当地的特色种类。

植物园的第一要务便是摸清家底, 制订长期规 划, 保护好、展示好珍贵的资源。这是对全人类负 责, 对全球生态系统负责的行动。要向公众传达这 样的思想: 本土种是好的、美的, 值得保护的; 外来 种则不同, 可能无害也可能问题非常大, 不能因一 时冲动而随便引种。植物园可以引导人们监测当地 的入侵种, 比如在北京要注意三裂叶豚草(Ambrosia trifida)、豚草(A. artemisiifolia)、刺果瓜(Sicyos angulatus)、黄顶菊(Flaveria bidentis)、鸡矢藤 $(P a-$ ederia scandens)、印加孔雀草(Tagetes minuta)、香 丝草(Conyza bonariensis)、钻形紫苑(Aster subulatus)、光梗踒藜草(Cenchrus calyculatus)、刺蓦龙葵 (Solanum rostratum)、意大利苍耳(Xanthinm italicum) 的泛滥情况, 有时公众可以自己直接清除它们。

1955年中国引进奥勃罗契夫主编的《研究自己 的乡土》一书, 现在虽然一些具体描述已过时, 但 整部书的思想并未过时, 反而代表着一种新潮流。 现在完全可以编著同样题目的图书, 出版此类作品 有利于公众认识家园、热爱家园。目前, 本土植物 手册相当缺乏, 有条件的地区可以先做起来。本土 植物手册涉及的相似物种数较少, 初学者可以使用 排除法, 这便大大简化了物种辨识过程。《中国常见 植物野外识别手册》已经出版多部(山东册、衡山册、 
古田山册、祁连山册、苔藓册、荒漠册等) (马克平, 2010-2017), 如果此丛书全面覆盖中国国土, 极其 有利于公众了解本土植物。各大植物园均应公开出 版自己园区的植物手册。植物园内植物引种地图除 特殊保密外，也应当面向公众开放。

在现代社会中, 提倡向科学和科学家学习, 完 全正常并合理, 但是如果提倡向博物学家学习, 特 别是科学家带头向“远不如自己”的博物学家学习, 就有些难以理解。但是观念也在缓慢地变化, 《美国 科学家》杂志在纪念博物学家梭罗诞辰 200 周年之 际刊出的两篇文章表达了科学界对博物学的敬意 (Timblin, 2017; Pyle, 2017): 4位不同领域的科学家 分别描述了梭罗“肤浅的”博物探究的特点, 以及它 们如何颇具深意、变得不可替代。将梭罗的博物工 作摘编成个别现代科学思想的前驱或为当下科学 的某些关注点提供佐论, 从而把梭罗重新塑造成一 个了不起的科学家或前科学家, 这容易理解, 却忽 视了梭罗式探究、记录、描述的更广泛意义, 某种 程度上也是对梭罗的曲解。要知道, 梭罗对当时科 学界的一些做法已经提出过批评, 他本人以博物学 家自居，没想成为科学家。

对于普通人来说, 通过一定的学习成为博物学 家是完全可能的, 通过积累也可以做出与自己身份 相符的成果。但是, 只有极少数人能成为科学家。 植物园工作应当瞄准前者, 而不是后者。即使是科 普, 也应当重在使受众对自然、对科学产生兴趣, 而不是一开始就瞄准变成科学家、像科学家一样做 研究。一些涉及大量数据采集的知名科学项目如 National Phenology Network, Project Budburst, Journey North, eBird以及英国生物记录中心(BRC)的项 目都可以让稍稍接受训练的普通爱好者参与进来, 一方面为科学研究积累数据, 另一方面也改善了科 学与公众的关系。

实际上，发达国家经常使用的平民科学(citizen science)和平民科学家(citizen scientist)等概念主要 是针对博物类科学(植物学、植物园学显然属于此 类), 即普通百姓从博物视角的参与。它们有明显的 局限性(如深度不够、力量分散、组织杂乱等), 但也 有优势, 为公众在高技术时代能够以自己的方式探 究自然事物提供了窗口。这与博物学家梭罗在《瓦 尔登湖》《野果》《对种子的信念》中表达的思想一 致。一百多年后, 植物学家、生态学家、水利专家、
人类学家都从梭罗的作品中发现了珍宝，但显然梭 罗不是上述任何一个“家”，他只是喜欢以自己的方 式观察、记录、描写自己的家乡罢了。

要问博物学家梭罗对植物、对一株树的“探究” 究竟有何特别之处, 《美国科学家》的一篇文章作了 精彩回答: “在过去 25 年或更多的时间中，学者们不 断发掘梭罗记录的却还来不及提炼的极为丰富的 康科德物候观察。由于梭罗身后出版物中删除了这 些记录, 所以学者们需要一段时间消化这些数据。 林业领域也忽略了梭罗发表的关于演替和树木年 代学的成果, 却是由于另外一个原因。他们不相信 一位超验主义者的观察。虽说重新确认这些事实颇 重要, 但对科学家来说更为关键的是要认真领会梭 罗的思想: 事实只是事情的一部分。当梭罗试图去 理解大自然，他充分意识到严格定量方法或微观视 角太狭窄，局限性很大，不足以把握整体，用梭罗 的话来说, 甚至不足以涵盖整体。梭罗看重科学, 但他总是将博物学家的精确观察与美学、哲学的领 悟相结合。梭罗想从自然事实层面了解一株树, 也 想从精神事实层面了解一株树。如此看世界不是很 棒吗?” (Richard Higgins的话, 转引自 Timblin, 2017)

\section{4 解放思想，全方位传播植物文化，而不仅 仅是植物知识}

科学传播有不同的模型和立场(刘华杰，2007; 杨舰和刘兵, 2010), 有些可能不是科学家非常认可 的。科学传播不单纯是科学自身的事情, 学界不应 以科学界的常规理念、标准要求一切。科学、科普 太重要了, 不宜只由科学工作者来担当。

首先，植物园面向公众进行传播时，应当明确 最终目标不是把听众、观众转化成植物学家一样的 人。只有极少数孩子长大后可能专攻植物学并以研 究植物谋生, 绝大多数人只是适当了解植物, 增长 见识，丰富日常生活。但是许多植物园工作者习惯 于用科学标准要求受众、衡量工作效果。从博物学 的角度调动和培育公众对植物的兴趣, 学习欣赏自 然之美，学会理解演化之精致，才是基本目的，也 更有亲和力。

在认知方面，植物园传播植物学文化宜超越唯 科学主义，在辨识植物过程中鼓励并培育“个人致 知”(personal knowing)和“赋比兴”的能力。充分利用 网络、数字化技术便利, 鼓励公众拍摄、手绘植物, 
建立个人植物档案。植物园工作者宜通过多种实例, 对公众讲述“访问”植物和植物研究成果的方法。科 学观上宜采用更宽容的表述, 如1999年布达佩斯世 界科学大会所提出的观点: “现代科学不是唯一的 知识, 应在这种知识与其他知识体系和途径之间建 立更密切的联系, 以使它们相得益彰” (转引自美国 科学、工程与公共政策委员会, 2004)。

个人知识(personal knowledge)和默会知识(tacit knowledge) 是科学哲学家波兰尼提出的概念。科学 知识生产是一个公共化过程, 通过同行评议、发表、 检验得以实现, 个人致知是其中一个重要环节。反 过来, 公众也是通过个人致知最终理解、消化公共 知识的。植物志、植物学期刊上的公共知识变成公 众的个人知识, 要经过个人致知这个中间环节: 植 物学公共知识 $\rightarrow$ 下载学习 $\rightarrow$ 个人致知 $\rightarrow$ 新的个人 知识。民间往往积累了大量本土知识 (indigenous knowledge, 包括食用、药用、仪式应用等), 近些年 受到了人类学家、民族植物学家的高度重视(张永宏, 2009; Cooper, 2010; 刘华杰, 2012)。洛克当年的植 物学作品中就注意收集植物的本土名, 但本土名在 我们这里似乎还没有引起足够重视。

其实, 植物学家分辨植物(严格鉴定除外)通常 也并非完全依照植物检索表来进行, 而是依据直 观、个人经验, 即某种个人知识。个人知识具有多 样性、不确定性、不可通约性, 但不意味着无用或 者完全不可靠。公众接触植物不是为了专门研究和 发表论文, 只要保证结果一致就可以了。发挥个人 对不同分类特征的敏感性专长, 辨识植物做到殊途 同归是应当鼓励的。比如在日常生活中讲香椿与臭 椿的区别, 就不必用检索表上的蒴果翅果了(一株 香椿小苗要长许多年才能结果), 在现实中有多种 有效办法将它们区别开来。也要鼓励民众自己发现 有效的区分办法。反过来看, 用果实形状来区分香 椿和臭椿, 是最简单不过的工作。

\section{5 走出藩篱: 多地开展植物导赏活动}

高水准的植物文化传播还要平衡驯化与野性 的矛盾, 使公众能够同时了解植物的栽培状态和自 然状况。与一些收玫取向相反, 植物园工作者应主 动打破原有的植物园边界, 不再局限于在围墙内、 篱笆内栽培、保护和展示植物。要尝试走出去, 以 园区为中心向外拓展。
首先, 地点要从固定的单一实体园扩展到网络 分布的子园、社区、校园、野地、步道。除少数必 须迁地保护外, 大部分物种宜就地保护, 如在北京 附近, 槭叶铁线莲(Clematis acerifolia)、北京水毛莨 (Batrachium pekinense)、长毛银莲花(Anemone narcissiflora var. crinita)、冀北翠雀花(Delphinium siwanense) 就不宜栽种在植物园中。在东北, 猪牙花 (Erythronium japonicum)、槭叶草(Mukdenia rossii)、 大叶子 (Astilboides tabularis)、侧金盏花 (Adonis amurensis)、多被银莲花(Anemone raddeana)、反萝 银莲花 (A. reflexa) 等也宜在野外观赏。它们的确非 常特别, 值得保护和观赏, 可以引导市民在野外观 看。就地保护符合植物的天性，也节约资金。可以 学习夏威夷的做法, 建立本土植物恢复区, 示范野 外物种保护, 鼓励公众参与维护(刘华杰, 2014)。原 来在一个范围内进行的植物科普、植物文化传播活 动, 可以扩展到本地区的全境。更重要的是, 此做 法提示公众, 植物在野外生长是恰当的、可持续的, 未必一定要移栽到某个园子中。一些民众喜欢采挖 野生植物到自己家栽种, 其做法形式上跟植物园引 种野生种类似，但民众通常不具备养护知识和技能， 最终大部分被采挖的植物无法成活。应当教育公众 见到美丽的植物要记住地点, 以后可以再来观赏, 不要采挖。公众如果习惯了在野地里欣赏植物, 既可 以锻炼身体，也能保护物种。这才是正道、大道。

其次, 可以把原有的植物园作为基地(驯化、宣 教、培育)向外辐射，在植物园网站和媒体上提前公 布一年内的户外植物导赏内容和路线, 吸引有特定 兴趣的植物爱好者参与。以北京为例, 可以策划到 门头沟和房山观赏特有种槭叶铁线莲(4月中下旬), 在昌平虎峪和兴寿静之湖、延庆松山和玉渡山、房 山白草畔、门头沟小龙门和灵山、怀柔雾灵山和喇 叭沟门、密云坡头等地设计多条北京本土植物观察 路线。这一方面扩展了植物园的“领地”, 另一方面 可积累物种及生态数据, 最终有助于了解、保护北 京的植物和生态环境。针对每条步道的导赏, 可开 发专门的印刷版与电子版植物指南、手册。实际上, 民间已经自发地开展了收费的相关活动，专业植物 园工作者应当与时俱进。步道植物导赏活动反过来 也可以推动京津冀及太行山地区的国家级步道系 统建设。发达国家几乎都有发达的步道系统。

总之, 改进植物文化传播, 对植物园工作方式 
和专业人员配置均提出了新要求, 需要转变观念, 逐步尝试。在扩展地盘、大幅增加实体园运营资金 有难度的情况下，这类改革也是一种机遇。

植物与公众关系十分密切, 我们的祖先虽然不 知道植物的学名和分科信息, 但仍然熟悉身边的植 物。作为后代我们有责任广泛、有效地传习多层面的 植物文化, 为公众在“生活世界” (一个现象学哲学 概念)中幸福地生活, 为天人系统可持续生存服务。

\section{参考文献}

Allen DE (translated by Chen X) (1994) The Naturalist in Britain: A Social History, 2nd edn. Princeton University Press, Princeton. [程尔(译) (2017) 不列颠博物学家: 一部社会 史. 上海交通大学出版社, 上海.]

Anderson JGT (2013) Deep Things Out of Darkness: A History of Natural History. University of California Press, Berkeley and Los Angeles.

Barber L (1980) The Heyday of Naturalist History (18201870). Doubleday \& Company, Inc., New York.

Bridson G (2008) The History of Natural History: An Annotated Bibliography, 2nd edn. Linnean Society of London, London.

Committee on Science, Engineering, and Public Policy (2004) On Being a Scientist: Responsible Conduct in Research. National Academies Press, Washington, DC. (in Chinese) [美 国科学、工程与公共政策委员会 (2004) 怎样当一名科学 家: 科学研究中的负责行为(中文版附录), 91页. 北京理 工大学出版社, 北京.]

Cooper A (2010) Inventing the Indigenous: Local Knowledge and Natural History in the Early Modern Europe. Cambridge University Press, Cambridge, New York.

Farber PL (2000) Finding Order in Nature: The Naturalist Tradition from Linnaeus to E. O. Wilson. The Johns Hopkins University Press, Baltimore and London.

French R (1994) Ancient Natural History. Routledge, London and New York.

Gay P (translated by Zhao Y) (2015) Education of the Senses, pp. 11-12. Century Publishing Group, Shanghai. (in Chinese) [赵勇 (译) (2015) 感官的教育, 11-12页. 世纪出版 集团, 上海.]

Graham MH, Parker J, Dayton P (2011) The Essential Naturalist: Timeless Readings in Natural History. University of Chicago Press, Chicago and London.

Hong DY (2016) Three "what": mission of a botanic garden.
Biodiversity Science, 24, 728. (in Chinese) [洪德元 (2016) 三个“哪些”：植物园的使命. 生物多样性, 24, 728.]

Jardine N, Secord JA, Spary EC (1996) Cultures of Natural History. Cambridge University Press, Cambridge.

Leopold A (1949) A Sand County Almanac and Sketches Here and There. p. viii (Preface). Oxford University Press, New York and Oxford.

Liu HJ (2012) Living as a Naturalist. Peking University Press, Beijing. (in Chinese) [刘华杰 (2012) 博物人生. 北京大学 出版社, 北京.]

Liu HJ (2014) Botanical Journeys in Hawaii, pp. 233-242, 252-255, 263-268. China Science and Technology Press, Beijing. (in Chinese) [刘华杰 (2014) 檀岛花事, 233-242, 252-255, 263-268页. 中国科学技术出版社, 北京.]

Liu HJ (2016) Cultures of Natural History and Historiographical Theory of Science. Shanghai Jiaotong University Press, Shanghai. (in Chinese) [刘华杰 (2016) 博物学文化 与编史. 上海交通大学出版社, 上海.]

Liu HJ (2017) On the revival of natural history and the future of ecological civilization. Frontiers, (3), 76-84. [刘华杰 (2017) 论博物学的复兴与未来生态文明. 学术前沿, (3), 76-84.]

Liu HJ (2007) Readings in Science Communication, pp.1-11. Shanghai Jiaotong University Press, Shanghai. (in Chinese) [刘华杰 (2007) 科学传播读本, 1-11页. 上海交通大学出 版社, 上海.]

Ma KP (2010-2017) Field Guide to Wild Plants of China, Series. Higher Education Press and Commercial Press, Beijing. (in Chinese) [马克平 (2010-2017) 中国常见植物野外识别 手册. 高等教育出版社、商务印书馆, 北京.]

Merrill LL (1989) The Romance of Victorian Natural History. Oxford University Press, New York and Oxford.

Pyle RM (2017) The niche of a naturalist. American Scientist, $105,252$.

Timblin D (2017) Thoreau as naturalist: a conversation with four authors. American Scientist, 105, 248.

Yang J, Liu B (2010) Social Operation of Science and Technology, pp.10-21. Tsinghua University Press, Beijing. (in Chinese) [杨舰, 刘兵 (2010) 科学技术的社会运行, 10-21页. 清华大学出版社, 北京.]

Zhang YH (2009) On the concept of indigenous knowledge. Thinking, (2), 3. (in Chinese) [张永宏 (2009) 本土知识概 念的界定. 思想战线, (2), 3.]

(责任编委：龙春林 责任编辑：时意专) 